\title{
Bahasa Indonesia Telah Diproklamasikan Sebagai Bahasa Internasional
}

\author{
Tri Budhi Sastrio
}

\begin{abstract}
ABSTRAK
Hampir empat tahun telah berlalu dan gema nyaring proklamasi bahasa Indonesia sebagai bahasa internasional tetap saja sayup-sayup meskipun diyakini seperti yang diamanatkan di dalam Proklamasi Bahasa - KBI X itu sendiri, semua berjalan secara alami menuju ke sebuah tujuan yang sebenarnya tidak tepat juga dikatakan tujuan karena tujuan itu telah dicapai dan bersama-sama dengan tujuan itulah semua berjalan sekarang ini. Makalah singkat berikut ini mencoba mencatat semua latar belakang peristiwa sederhana yang melatarbelakangi diproklamirkannya bahasa Indonesia sebagai bahasa Internasional, yang versi digitalnya diunggah melalui Facebook, sedangkan versi tertulisnya dimuat di dalam harian Tribunnews yang terbit di Kalimantan.
\end{abstract}

Kata kunci : Proklamasi Bahasa

\section{PENDAHULUAN}

Apakah ini tindakan main-main yang menjadi serius, atau tindakan serius yang dilakukan secara main-main? Proklamasi adalah tindakan serius, termasuk Proklamasi Bahasa, termasuk juga Proklamasi Bahasa yang diproklamasikan dari Poznan, Polandia, pada 28 Oktober 2013. Jadi tentu saja ini bukan main-main. Ini tindakan serius, bahkan amat serius. Jika pun unsur main-main ingin dimasukkan ke dalam hal yang sangat serius seperti Proklamasi Bahasa - KBI X, maka unsur main-main ini harus berada dalam bingkai unsur proklamasi yang serius. Unsur mainmain harus tunduk pada unsur serius. Unsur main-main memproklamasikan Bahasa Indonesia sebagai bahasa internasional dengan gaya dan bentuk mengadaptasi gaya dan bentuk Proklamasi Kemerdekaan akan luruh dan larut dengan sendirinya ke dalam gaya dan bentuk yang sangat serius dari Proklamasi Kemerdekaan.

Dengan memperhatikan beragam versi Proklamasi Kemerdekaan negara, mulai dari yang tulisan tangan, diketik dengan mesin ketik, dan yang dicetak dalam mata uang berikut ini secara lebih saksama, kemudian dibandingkan dengan dua versi Proklamasi Bahasa - KBI X, yang satu versi Facebook dan yang satunya lagi versi cetak pada salah satu harian, diharapkan suasana kebatinan keduanya dapat ditaut-kelindankan sehingga penjelasan lanjutannya, jika memang boleh dianggap sebagai penjelasan lanjutan, dapat lebih dipahami. Untuk yang versi cetak, dalam file PDF 
dapat dilihat pada tautan yang disertakan dalam daftar pustaka dengan penanda Naskah Proklamasi Bahasa yang ditulis dengan huruf miring.

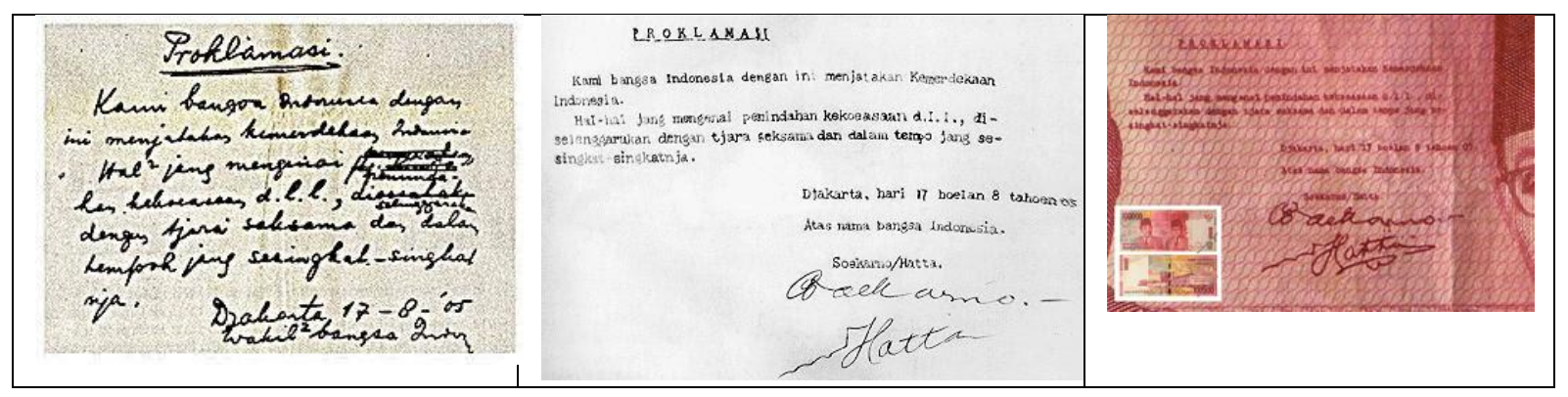

\section{PROKLAMASI BAHASA}

Kami, peserta Kongres Bahasa Indonesia $\mathrm{X}$ dan penutur serta pengguna bahasa Indonesia di seluruh dunia, memproklamasikan Bahasa Indonesia sebagai bahasa internasional. Semua hal yang berkaitan dengan tindak lanjut proklamasi ini akan dilaksanakan secara gotong-royong dan dalam tempo yang tidak ada batasannya. Poznan - Jakarta, 28 Oktober 2013

Atas nama peserta KBI X, penutur dan pengguna $\mathrm{BI}$ ttd

Dr. Tri Budhi Sastrio

\section{PROKLAMASI BAHASA}

Kami, peserta Kongres Bahasa Indonesia X dan penutur serta pengguna bahasa Indonesia di seluruh dunia, memproklamasikan Bahasa Indonesia sebagai bahasa internasional. Semua hal yang berkaitan dengan tindak lanjut proklamasi ini akan dilaksanakan secara gotong-royong dan dalam tempo yang tidak ada batasannya.

Poznan - Jakarta, 28 Oktober 2013

Atas nama peserta KBI X, penutur dan pengguna BI ttd

Dr. Tri Budhi Sastrio

Lalu suasana kebatinan apa yang sebenarnya bertaut antara dua versi 'proklamasi' ini? Yang pertama menyatakan bahwa Indonesia telah merdeka, sedangkan yang kedua menyatakan bahwa bahasa Indonesia telah menjadi bahasa internasional. Mana yang lebih gagah dan berwibawa? Tentu saja yang pertama. Mana yang lebih hebat perbawanya? Tentu saja yang pertama. Mana yang lebih ini, mana yang lebih itu? Tentu saja yang pertama. Dengan kata lain, proklamasi yang pertama benar- 
benar serius, bahkan sangat serius, sedangkan proklamasi yang kedua proklamasi bahasa - lebih kental nuansa main-mainnya. Lalu apa yang sama antara keduanya, jika memang ada yang sama? Sebagai sebuah dokumen tertulis, keduanya adalah keniscayaan, keduanya sama sahnya, keduanya sama-sama mempunyai sifat atau karakter 'apa yang sudah tertulis biarlah tetap tertulis'.

\section{PEMBAHASAN}

\section{Bahasa Internasional - Antara Cita-Cita dan Realita}

Prof. Berthold Damhauser, pengajar Bahasa dan Sastra Indonesia di Universitas Bonn mengatakan, ada berbagai syarat untuk menjadi sebuah bahasa internasional. Antara lain, bahasa tersebut harus digunakan dalam diplomasi dan perdagangan Internasional, berperan dalam penyebaran ilmu pengetahuan, kesederhanaan sistem bunyi dan gramatikalnya sehingga mudah dipelajari, tinggi budi dan peradabannya, dan pemiliknya harus memiliki rasa percaya diri serta peduli terhadap bahasanya sendiri.

Pernyataan guru besar ini entah sudah berapa kali dikutip oleh para cendekiawan Indonesia, dan yang paling baru dikutip oleh RRI, katanya dalam rangka memperingati bulan Oktober 2017, bulan bahasa, seperti yang tampak dalam tautan berikut, dan biasanya disertai oleh banyak retorika, yang menyatakan bahwa bahasa Indonesia sejatinya telah memenuhi semua persyaratan tersebut:

http://rri.co.id/lhokseumawe/post/berita/443526/komentar_voice_of_indon esia/bahasa_indonesia_menuju_bahasa_internasional.html

Hanya saja apa yang terjadi? Apakah bahasa Indonesia telah menjadi bahasa internasional dengan semua retorika tersebut? Tidak. Sebagian besar orang yang ditanya, biasanya orang-orang yang sangat terpelajar dan cerdik cendika, menyatakan bahasa Indonesia belum menjadi bahasa internasional karena alasan ini, karena alasan itu, dan sejumlah argumen lainnya. Singkat kata bahasa Indonesia belum menjadi bahasa internasional, itu kata mereka. Kata Proklamasi Bahasa di atas, bahasa Indonesia telah menjadi bahasa internasional sejak 28 Oktober 2013, sejak diproklamasikannya bahasa Indonesia menjadi bahasa internasional melalui Proklamasi Bahasa yang diunggah ke dunia maya dari kota Poznan, Polandia, dan dicetak di media cetak di Kalimantan, Indonesia.

Berikutnya, berkaitan dengan undang-undang milik kita sendiri.

Dalam UU no 24 tahun 2009 tentang Bendera, Bahasa dan Lambang Negara, pasal 44 ayat 1 hingga 3 disebutkan pemerintah meningkatkan fungsi Bahasa Indonesia menjadi bahasa internasional secara bertahap, 
sistematis dan berkelanjutan. Ayat kedua menyebutkan peningkatan fungsi Bahasa Indonesia menjadi bahasa internasional sebagaimana dimaksud pada ayat satu dikoordinasi oleh lembaga kebahasaan. Sedangkan ayat ketiga, ketentuan lebih lanjut mengenai peningkatan fungsi Bahasa Indonesia menjadi bahasa internasional sebagaimana dimaksud pada ayat satu diatur dalam peraturan pemerintah.

Setelah delapan tahun lebih berlalu sejak UU no. 24/2009 ini diundangkan, apakah bahasa Indonesia telah menjadi bahasa internasional? Belum. Mengapa? Apakah karena ada amanat bertahap, sistematis dan berkelanjutan? Mungkin saja tetapi jika konsep 'bertahap, sistematis dan berkelanjutan' diterapkan untuk Proklamasi Kemerdekaan, mungkin sampai sekarang masih saja ada kendala agar negara ini dapat segera merdeka. Tentu saja konsep 'bertahap, sistematis dan berkelanjutan' bagus, bahkan sangat bagus, tetapi tidak semua harus diawali dan dibingkai oleh tiga hal ini. Diperlukan sesuatu yang ugalugalan, yang main-main tetapi serius, yang 'bonek', agar sesuatu yang penting dapat segera diwujudkan. Apa itu? Ya proklamasikan saja lebih dulu, yang lain-lain bisa dilakukan kemudian, apalagi jika yang lain-lain tersebut diamanatkan 'dalam tempo yang tidak ada batasannya'.

Jadi jika UU no. 24/2009 jelas-jelas belum berhasil menjadikan bahasa Indonesia menjadi bahasa internasional, maka Proklamasi Bahasa berhasil menjadikan bahasa Indonesia sebagai bahasa internasional hanya dalam kurun waktu tidak lebih dari empat tahun. Kata Proklamasi Bahasa di atas, bahasa Indonesia telah menjadi bahasa internasional sejak 28 Oktober 2013, sejak diproklamasikannya bahasa Indonesia menjadi bahasa internasional melalui Proklamasi Bahasa yang diunggah ke dunia maya dari kota Poznan, Polandia, dan dicetak di media cetak di Kalimantan, Indonesia.

Berikutnya berkaitan dengan bahasa internasional resmi yang digunakan oleh PBB.

Sejauh ini ada enam bahasa diakui sebagai bahasa resmi PBB, yaitu Bahasa Inggris, Bahasa Arab, Bahasa Mandarin, Bahasa Spanyol, Bahasa Rusia dan Bahasa Perancis. Belum ada bahasa ketujuh yang diakui oleh PBB sebagai bahasa resmi. Banyak otoritas bahasa di Indonesia yang dalam retorikanya menyatakan sedang berusaha menjadikan bahasa Indonesia sebagai bahasa ketujuh. Mungkin saja, suatu ketika nanti usaha ini akan membuahkan hasil, dan bahasa Indonesia menjadi bahasa resmi ketujuh di badan dunia itu. Mungkin saja, akan tetapi usaha menjadikan bahasa resmi PBB tidak akan pernah berhasil jika bahasa Indonesia tidak menjadi bahasa internasional lebih. Kapan langkah penting menjadi 
bahasa internasional ini menjadi kenyataan jika hanya retorika yang cetar membahana? Proklamasi Bahasa sudah menyelesaikan langkah penting tersebut sejak 2013. Kata Proklamasi Bahasa di atas, bahasa Indonesia telah menjadi bahasa internasional sejak 28 Oktober 2013, sejak diproklamasikannya bahasa Indonesia menjadi bahasa internasional melalui Proklamasi Bahasa yang diunggah ke dunia maya dari kota Poznan, Polandia, dan dicetak di media cetak di Kalimantan, Indonesia.

Tidak perlu menjadi bahasa resmi ketujuh segala, cukup menjadi bahasa internasional dulu, dan ini sudah menjadi fakta, maka berikutnya jika semua orang mau bersatu padu menggelorakannya maka semua pintu dan jendela akan terbuka dengan sendirinya.

Berikutnya berkaitan dengan faktor kesulitan penguasaan bahasa Indonesia dibandingkan dengan bahasa lain.

Dari sebuah situs pribadi milik Ulfa Melvina, grafik balok yang dikutip dari sebuah sumber tertentu, tampak jelas bahwa dua bahasa yang faktor kesulitan untuk dikuasai mencapai angka 2200 jam, ternyata berhasil menjadi bahasa resmi PBB yang sekaligus bermakna menjadi bahasa internasional. Jadi jelas bahwa faktor kesulitan sama sekali bukan faktor penentu agar sebuah bahasa menjadi bahasa internasional. Lalu apa faktor penentunya? Jika sang guru besar dari Universitas Bonn yang dijadikan rujukannya, ya banyak. Hanya saja jika dari yang banyak itu sudah semua dipenuhi tetapi tetap saja bahasa tersebut belum menjadi bahasa internasional, lalu apa yang salah? Apakah kriterianya yang kurang atau si pemilik bahasa yang mau bahasanya dijadikan bahasa internasional tetapi cara dan gayanya bertele-tele? Dalam kasus bahasa Indonesia, kriteria sang guru besar memang kurang dan pemilik bahasa bahasa ini yang terlalu lamban dan bertele-tele. Jika dua hal ini diperbaiki, kriteria ditambah, dan langkah nyata dilakukan segera, maka persoalan selesai.

Kriteria yang perlu ditambahkan adalah kriteria 'adanya proklamasi bahasa', dan langkah nyata yang perlu segera dilakukan adalah 'menduniakan proklamasi bahasa' tersebut. Kata Proklamasi Bahasa di atas, bahasa Indonesia telah menjadi bahasa internasional sejak 28 Oktober 2013, sejak diproklamasikannya bahasa Indonesia menjadi bahasa internasional melalui Proklamasi Bahasa yang diunggah ke dunia maya dari kota Poznan, Polandia, dan dicetak di media cetak di Kalimantan, Indonesia. 


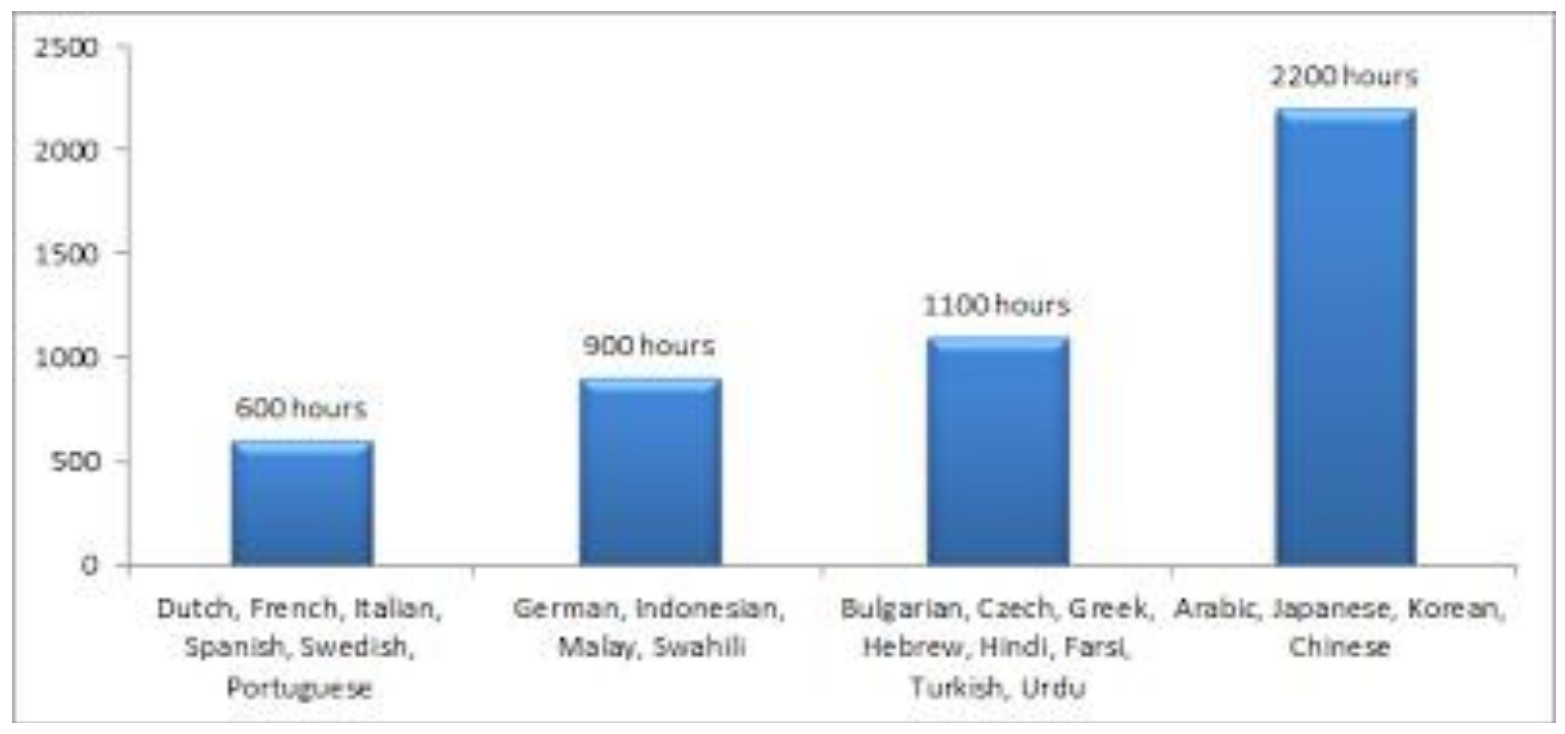

Perbincangan lanjutan bisa dilakukan, dengan beragam argumen dan langkah-langkah persiapan seperti yang diamanatkan UU no. 24/2009 yaitu 'bertahap, sistematis dan berkelanjutan' tetapi hendaknya itu semua dibingkai dalam satu pemikiran 'ugal-ugalan walau tetap sederhana' yaitu: Kata Proklamasi Bahasa di atas, bahasa Indonesia telah menjadi bahasa internasional sejak 28 Oktober 2013, sejak diproklamasikannya bahasa Indonesia menjadi bahasa internasional melalui Proklamasi Bahasa yang diunggah ke dunia maya dari kota Poznan, Polandia, dan dicetak di media cetak di Kalimantan, Indonesia.

\section{SIMPULAN}

Semua langkah yang 'bertahap, sistematis dan berkelanjutan' memang harus diserahkan pada para ahlinya terutama pada mereka yang oleh negara ditugasi untuk melaksanakan itu, dan semuanya silahkan diatur. Hanya saja jangan lupa bahwa: Kata Proklamasi Bahasa di atas, bahasa Indonesia telah menjadi bahasa internasional sejak 28 Oktober 2013, sejak diproklamasikannya bahasa Indonesia menjadi bahasa internasional melalui Proklamasi Bahasa yang diunggah ke dunia maya dari kota Poznan, Polandia, dan dicetak di media cetak di Kalimantan, Indonesia.

Bersama-sama dengan seluruh penutur bahasa Indonesia di seluruh dunia, Proklamasi Bahasa boleh dikenang sambil diberitakan, sedangkan sebagai tuan rumah sekaligus pemilik bahasa internasional sudah selayaknya dan sepatutnya jika bahasa Indonesia yang sudah menjadi bahasa internasional ini diutamakan, bahasa-bahasa daerahnya dilestarikan, dan sebanyak mungkin bahasa asing dikenali dan dikuasai. 


\section{DAFTAR PUSTAKA}

http://www.webkeren.net/2014/08/teks-proklamasi-kemerdekaanindonesia-17-agustus-1945-lengkap.html

https://lookaside.fbsbx.com/file/Proklamasi\%20Bahasa\%20\%202.pdf?token=AWxrSm8fGqJ2NjbsWmYGNRutfmAj72acztFFExbW_8uScWUxu4GriyGTQOxqQ3vYd7XaQgamwW2RybxZRSzxTEZNna0h5e5FuNu5lEQkTSZtpWO0p5xnY-VS2bMd15f1ZoqJL21LTlk2vA06fGlsf (Naskah Proklamasi Bahasa)

https://lookaside.fbsbx.com/file/Proklamasi\%20Bahasa\%20\%201.pdf?token=AWwI78INps5GsS0OA7DwgugjDHVwGx80Vyd8Q5 N yWMwkH51JLTpdlQ8h-BIXpAsALRm1n85Oej5KwaLugIrDH rHjq8U5pzSeANMMC9yndTKsaeVUfp0y9nS7SeJnuBZ2x9kcWLk_G7qbuUMj7GRG

http://ulfamvn.blogspot.co.id/2013/04/siapa-bahasa-internasionalselanjutnya.html (Ulfa Melvina)

http://rri.co.id/lhokseumawe/post/berita/443526/komentar_voice_of_indon esia/bahasa_indonesia_menuju_bahasa_internasional.html (Berita RRI dalam rangka bulan bahasa Oktober 2017) 